\title{
Comparison of Functional and Radiological Outcomes of Olecranon Fractures Treated with Tension Band Wiring with Kirschner Wires to Transcortical Screw Fixation-A Randomised Controlled Study
}

Siddhartha Sinha ${ }^{1}$, Rajiv Maharjan ${ }^{2}$, Guru P Khanal ${ }^{3}$, Bishnu Pokharel ${ }^{4}$, Nikhil Drolia ${ }^{5}$, Sumit Gupta ${ }^{6}$, Rajesh K Kanojia ${ }^{7}$, Pashupati Chaudhary ${ }^{8}$

\begin{abstract}
Aim: To compare the clinical and radiological outcomes of fixation of olecranon fractures by a transcortical screw with conventional tension band wiring (TBW) using a Kirschner wire (K-wire).

Material and methods: This is a non-blinded randomised controlled trial comprising two groups ( $n=30$ each) with Mayo type A olecranon fractures fixed with either TBW or transcortical cancellous screws (CCS). Outcomes included the Mayo elbow performance index (MEPI), time to union, range of motion (ROM), and rates of complication among these two groups.

Results: Most of the patients showed excellent scoring as per MEPI in both the groups at 6 weeks (90\% in TBW group and $76.7 \%$ in CCS group) and were not significant $(p=0.719)$. Signs of the radiological union were noted in $80 \%$ of the cases at 6 weeks and complete at 6 months. Hardware-related complications (8.3\% symptomatic hardware and $6.7 \%$ implant back-out), infection, and mean ROM were similar between the two groups (elbow flexion was $142.33 \pm 24.67^{\circ}$ in TBW group and $143.1 \pm 10.19^{\circ}$ in transcortical screw group, $p=0.246$ ) at the end of the study. Conclusion: There were no statistically significant differences in the clinical-radiological outcomes and complications fixing the non-comminuted olecranon fractures with either transcortical screw or TBW.

Clinical significance: Transcortical screw fixation is an acceptable alternative to TBW for non-comminuted olecranon fractures in terms of union and functional outcome.

Keywords: Bone screws, Elbow, Fracture fixation, Olecranon fracture, Randomised controlled trial.

Strategies in Trauma and Limb Reconstruction (2020): 10.5005/jp-journals-10080-1510
\end{abstract}

\section{INTRODUCTION}

Olecranon fractures are intra-articular fractures accounting for $10 \%$ of all upper limb injuries. ${ }^{1}$ The primary aim of treatment is to restore function without pain. Tension band wiring (TBW) is the preferred treatment option for most non-comminuted fractures due to ease of technique and good outcomes. ${ }^{1-6}$ Complications of this technique include median nerve palsy, hardware prominence, hardware backout, and symptoms from the retained implant. ${ }^{4,7}$ Alternate methods of fixation have been studied to reduce these complications. ${ }^{8-12}$ Very few studies have investigated the use of $4.0-\mathrm{mm}$ screws for fixation with most published research based on a small number of patients, cadaveric studies, or synthetic bone constructs. ${ }^{4,9,13}$

Our aim was to compare the clinical and the radiological outcomes of olecranon fractures fixed using two 4.5- $\mathrm{mm}$ partially threaded transcortical screws (CCS) to the conventional TBW with K-wire by measuring the Mayo elbow performance index (MEPI) scoring, rates of union, and post-operative complications.

\section{Material and Methods}

This study was a non-blinded randomised controlled trial conducted in a university-based tertiary care hospital from March 2015 to February 2016 after ethical clearance from the institutional review committee. Based on the study by Woods
1,6,7 Department of Orthopaedics, Lady Hardinge Medical College, New Delhi, India

${ }^{2-4,8}$ Department of Orthopaedics, B P Koirala Institute of Health Sciences, Dharan, Nepal

${ }^{5}$ Patliputra Multispeciality Hospital, Dhanbad, Jharkhand, India

Corresponding Author: Siddhartha Sinha, Department of Orthopaedics, Lady Hardinge Medical College, New Delhi, India, Phone: +91 9871149503, e-mail: siddharthasinha87@gmail.com

How to cite this article: Sinha S, Maharjan R, Khanal GP, et al. Comparison of Functional and Radiological Outcomes of Olecranon Fractures Treated with Tension Band Wiring with Kirschner Wires to Transcortical Screw Fixation-A Randomised Controlled Study. Strategies Trauma Limb Reconstr 2020;15(3):131-137.

Source of support: Nil

Conflict of interest: None

et al., ${ }^{12}$ using Epi Info 7 the minimum sample size calculated was 60. Randomisation sequence was generated using Microsoft Excel random number generation technique. Eligible patients were fixed either with TBW $(n=30)$ or two 4.0-mm CCS with washer $(n=30)$. No blinding was done for surgeon, patient, or recorder. Adults (>16 years) with closed, Gustilo grade I or II open non-comminuted and isolated olecranon fractures (Mayo type IA, 
IIA, or IIIA) having either transverse, oblique superior, or oblique inferior fracture configurations were included. Comminuted fracture patterns (Mayo type IB, IIB, and IIIB), Gustilo grade III open fractures, fractures with neurovascular compromise, compartment syndrome, and patients not willing to participate were excluded from the study. After the initial management of fracture in the emergency department, pre-anaesthetic investigations were followed by an assessment for fitness for anaesthesia. The type of procedure was predetermined by randomisation and appropriate pre-operative planning was done. A posterior midline approach was utilised for exposure of the fracture. For TBW group, two parallel K-wires and a tension band construct using $16 \mathrm{G}$ stainless steel wire were used (Fig. 1). For the CCS group, two parallel 4.0-mm cannulated CCSs with washer were used (Fig. 2). In accordance with fracture fixation principles, the hardware was directed as perpendicular as possible to the fracture site obtaining hold in the far cortex. Post-operative radiographs were obtained after surgery. Physiotherapy started to prevent elbow stiffness as soon as the patient could

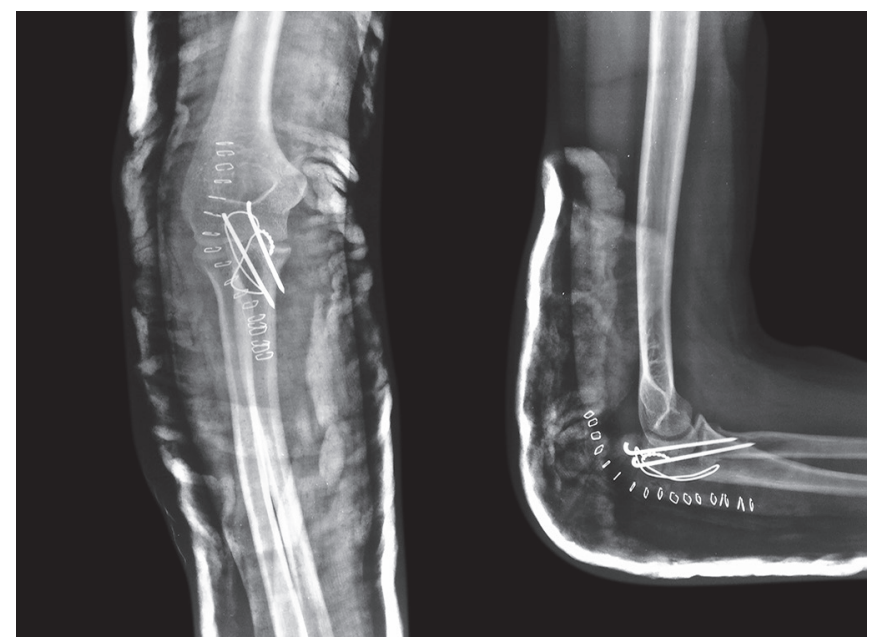

Fig. 1: Post-operative radiograph showing fixation using tension band wiring technique.

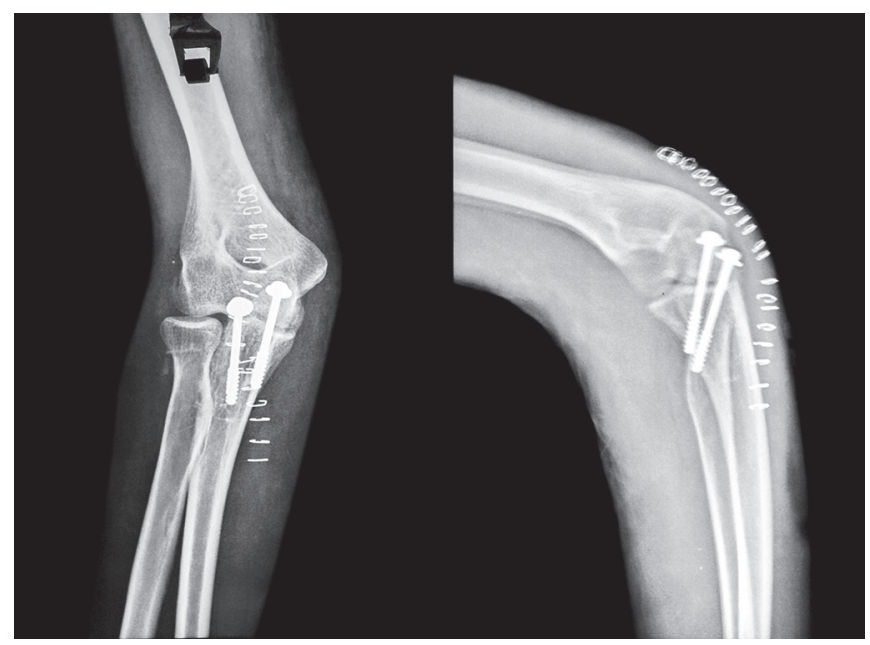

Fig. 2: Post-operative radiograph showing fixation using two $4.5 \mathrm{~mm}$ cannulated screws. tolerate it. Wound inspection and dressing were done and the patient was discharged on the 2 nd post-operative day if no other complications were present. The first follow-up was after 2 weeks for suture removal, surgical site assessment, initiating physiotherapy, and recording range of motion (ROM). Patients were followed at intervals of 6,12 , and 24 weeks. On each follow-up, neurovascular status, extensor lag, visual analogue scale (VAS), ROM, MEPI, examination for hardware complications, radiological assessment for the adequacy of fixation, signs of union, and myositic mass were assessed. Complications were subdivided into surgical, functional, and hardware related. Surgical complications included post-operative infection, damage to neurovascular structures, haemorrhage, loss of fixation, need for re-surgery, and implant removal. Functional complications included elbow stiffness, elbow pain, elbow instability, and late osteoarthritis of the elbow joint. Hardware-related complications included hardware prominence, hardware back-out, hardware breakage, and symptomatic hardware.

All data evaluation and collection were done by a single individual. The collected data were entered in Microsoft Excel 2007/2010 and converted into SPSS (Statistical Package for the Social Sciences) 20 version for statistical analysis. Descriptive analysis included calculation of mean and standard deviation, proportion, and percentage. Chi-square test, $T$-test (for parametric data), or Mann-Whitney $U$-test (for non-parametric data) were applied to find out the significant differences between the two groups for inferential analysis.

\section{Results}

A total of 70 patients presented during the study period with olecranon fractures; of these, four were excluded. A total of 66 patients who fulfilled the inclusion criteria were taken as the total sample size. Thirty-three patients each were randomised into TBW (group A) and CCS (group B) groups. Of the total number, six patients were lost to follow-up (Fig. 3).

A total of 30 cases in each group were assessed for the final analysis. One patient in group B developed a post-operative anterior interosseous nerve palsy possibly due to an injury while inserting screws. This was managed conservatively as the patient showed improvement on 12th week post-surgery and recovered on the 24th week follow-up.

The total number of males in the study were $39(65 \%)$ and females were 21 (35\%). In $61.7 \%(n=37)$, the right side was more commonly injured. The most common cause of injury was road traffic accidents (RTAs) accounting for 22 (36.7\%) injuries. In both groups, there were $25(83.3 \%)$ closed fractures. The most common fracture pattern in our study was oblique superior (41.66\%). There was no statistically significant difference between the two groups in terms of sex, mode of injury, type of fracture, fracture pattern, and side indicating that the randomisation was successful. A subset analysis for specific outcomes with respect to fracture pattern was not done (Table 1).

MEPI on the 6th post-operative week for the total sample size showed that 21 (35\%) had good scores and 26 (43.3\%) had excellent scores. On the 24 th post-operative week $90 \%(n=27)$ in group A and $76.7 \%(n=23)$ in group B reported excellent scores $(p=0.166)$. No significant differences in the MEPI were noted between the two groups for any follow-ups (Table 2).

There were no statistically significant differences in the rates of infection between the two groups for the entire study period. On the 2 nd post-operative day one (1.7\%) patient from the CCS group 


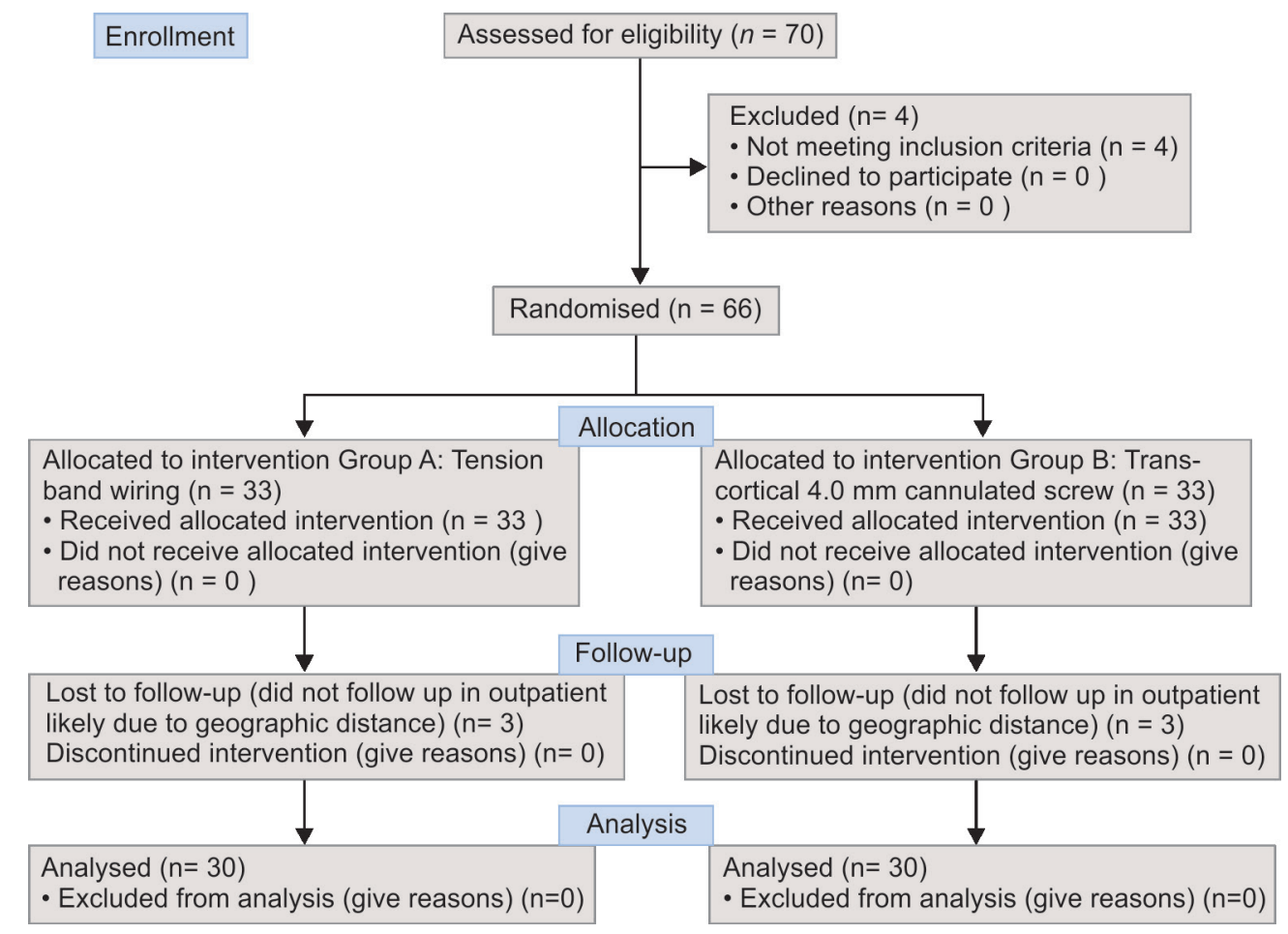

Fig. 3: CONSORT flow diagram of the study

Table 1: Demographic data of the study

\begin{tabular}{|c|c|c|c|c|c|}
\hline \multirow[b]{2}{*}{ Characteristics } & & \multicolumn{2}{|c|}{ Study group } & \multirow[b]{2}{*}{ Total (\%) } & \multirow[b]{2}{*}{$p$ value } \\
\hline & & Tension band wiring $(n=\%)$ & CC screw $(n=\%)$ & & \\
\hline Mean age \pm S.D. & & $36.666 \pm 13.862$ & $38.7667 \pm 15.230$ & - & 0.579 \\
\hline \multirow[t]{2}{*}{ Sex } & Male & $20(66.7)$ & $19(63.3)$ & $39(65)$ & 0.787 \\
\hline & Female & $10(33.3)$ & $11(36.7)$ & $21(35)$ & \\
\hline \multirow[t]{4}{*}{ Mode } & RTA & $14(46.7)$ & $8(26.7)$ & $22(36.7)$ & 0.424 \\
\hline & Fall from height & $3(10)$ & $4(13.3)$ & $7(11.7)$ & \\
\hline & Slip on ground & $9(30)$ & $11(36.7)$ & $20(33.3)$ & \\
\hline & Physical assault & $4(13.3)$ & $7(23.3)$ & $11(18.3)$ & \\
\hline \multirow[t]{3}{*}{ Open/closed } & Closed & $25(83.3)$ & $25(83.3)$ & $50(83.3)$ & 0.819 \\
\hline & Gustilo grade I & $3(10)$ & $2(6.7)$ & $5(8.3)$ & \\
\hline & Gustilo grade II & $2(6.7)$ & $3(10)$ & $5(8.3)$ & \\
\hline \multirow[t]{2}{*}{ Side } & Right & $17(56.7)$ & $20(66.7)$ & $37(61.7)$ & 0.426 \\
\hline & Left & $13(43.3)$ & $10(33.3)$ & $23(38.3)$ & \\
\hline \multirow[t]{3}{*}{ Type of fracture } & Transverse & $8(26.6)$ & $9(30)$ & $17(28.3)$ & 0.199 \\
\hline & Oblique superior & $12(40)$ & $13(43.3)$ & $25(41.66)$ & \\
\hline & Oblique inferior & $10(33.3)$ & $8(26.6)$ & $18(30)$ & \\
\hline
\end{tabular}

showed signs of infection which was managed conservatively with intravenous antibiotics. In the 2nd post-operative week, two patients from the TBW group showed signs of infection which were managed successfully with a 1-week course of antibiotics. No surgical intervention was required for the infections. None of the patients showed signs of infection after 2 weeks.

Radiological signs of union were seen in 50 (83.3\%) patients on the 6th post-operative week in the whole study group. At 24th post-operative week, all patients showed radiological signs of union. There was no statistically significant difference in the time of union between the two groups for any follow-ups (Fig. 4).

The rate of symptomatic hardware was $8.3 \%$ and the implant back-out was $6.7 \%$. The cases of back-out were not clinically significant to warrant immediate removal. There was no statistically significant difference in hardware complications among the two groups over the course of the study (Table 3 ).

VAS score was measured for patients up to 6 weeks as most experienced no or minimal pain after that. On the 2 nd post-operative 
Table 2: Mayo elbow performance index for each follow-up

\begin{tabular}{|c|c|c|c|c|c|}
\hline \multirow[b]{2}{*}{ Post-operative days } & \multirow[b]{2}{*}{ Mayo elbow performance index (MEPI) } & \multicolumn{2}{|c|}{ Groups } & \multirow[b]{2}{*}{ Total $(n=\%)$} & \multirow[b]{2}{*}{$p$ value } \\
\hline & & TBW group $(n=\%)$ & CC screw $(n=\%)$ & & \\
\hline \multirow[t]{4}{*}{ 2nd Post-operative day } & Poor & $29(96.7)$ & $30(100)$ & $59(98.3)$ & 0.313 \\
\hline & Fair & $1(3.3)$ & $0(0)$ & $1(1.7)$ & \\
\hline & Good & $0(0)$ & $0(0)$ & $0(0)$ & - \\
\hline & Excellent & $0(0)$ & $0(0)$ & $0(0)$ & - \\
\hline \multirow[t]{4}{*}{2 Weeks } & Poor & $13(43.3)$ & $14(46.7)$ & $27(45)$ & 0.559 \\
\hline & Fair & $17(56.7)$ & $15(50)$ & $32(53.3)$ & \\
\hline & Good & $0(0)$ & $1(3.3)$ & $1(1.7)$ & - \\
\hline & Excellent & $0(0)$ & $0(0)$ & $0(0)$ & - \\
\hline \multirow[t]{4}{*}{6 Weeks } & Poor & $0(0)$ & $0(0)$ & $0(0)$ & - \\
\hline & Fair & 7 (23.3) & $6(20)$ & 13 (21.7) & 0.719 \\
\hline & Good & $9(30)$ & $12(40)$ & $21(35)$ & \\
\hline & Excellent & $14(46.7)$ & $12(40)$ & $26(43.3)$ & \\
\hline \multirow[t]{4}{*}{12 Weeks } & Poor & $0(0)$ & $0(0)$ & $0(0)$ & - \\
\hline & Fair & $2(6.7)$ & $3(10)$ & $5(8.3)$ & 0.428 \\
\hline & Good & $16(53.3)$ & $11(36.7)$ & $27(45)$ & \\
\hline & Excellent & $12(40)$ & $16(53.3)$ & $28(46.7)$ & \\
\hline \multirow[t]{4}{*}{24 Weeks } & Poor & $0(0)$ & $0(0)$ & $0(0)$ & - \\
\hline & Fair & $0(0)$ & $0(0)$ & $0(0)$ & - \\
\hline & Good & $3(10)$ & $7(23.3)$ & $10(16.7)$ & 0.166 \\
\hline & Excellent & $27(90)$ & 23 (76.7) & $50(83.3)$ & \\
\hline
\end{tabular}

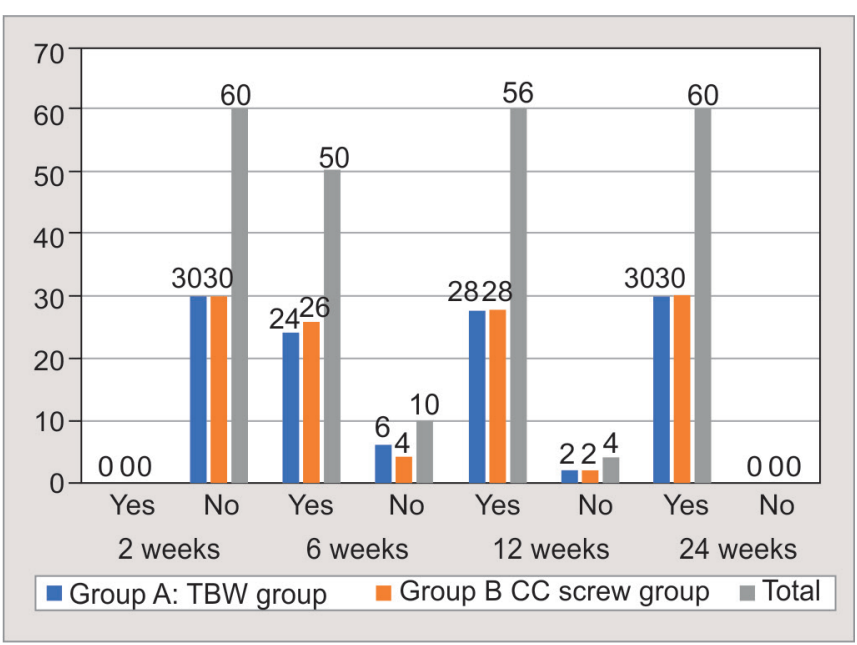

Fig. 4: Signs of union in both groups for each follow-up

day, the mean VAS score was $7.63 \pm 0.614$ in the TBW group and $7.36 \pm 0.490$ in the CCS group. The mean VAS score for the whole sample was $7.5 \pm 0.567$. (Mann-Whitney $U=0.088$ ) and there was no significant difference in the score among the two groups (Fig. 5).

The mean ROM progressively improved on each follow-up for both groups. ROM in group A was $142.33 \pm 16.11^{\circ}$ and group $B$ was $143.1 \pm 10.19^{\circ}$ at the end of the study $(p=0.246)$. No statistically significant difference in ROM was noted among the two groups (Fig. 6).

None of the patients reported implant failure, loss of fixation, extensor lag, or development of a myositic mass in both groups for the duration of the study.

\section{Discussion}

Methods of fixation for the olecranon fractures are a matter of debate with many implant choices and configurations being studied. TBW although technically simple has been proven to have higher incidences of complications. Many biomechanical studies have also shown that the compression at the fracture site is inferior to other methods. As a result, alternative methods of fixation have been explored with varying results. ${ }^{4,5,8,9,11,12,14}$ Studies exploring the use of a single $6.5-\mathrm{mm}$ partially threaded screw or construct using smaller compression screws to replace K-wire in the TBW construct have been performed showing lesser incidences of complications. ${ }^{8-12,15}$

Using 4.5-mm cannulated screws have the advantage of lesser soft tissue dissection, the possibility of performing a percutaneous procedure, better compression at the fracture site, early mobilisation, and lesser surgical time. Two screws also theoretically improve the rotational stability of the construct. However, recent studies show that there is often no statistical difference in the final outcomes for the patient. ${ }^{4,11,13}$ Despite the advantages, there is a possibility of jeopardising the proximal fragment by inserting two screws. ${ }^{13}$

The study sample had a male predominance with the right limb being more frequently injured. The most common mechanism of injury was following a RTA and similar fracture patterns were noted in both groups. Randomisation was successful as there were no significant differences between the two groups for the epidemiological parameters. The results of this study approximate the epidemiological findings by other authors. $3,11,16,17$

MEPI improved on each follow-up in both groups. Group A had excellent results in 90\% $(n=27)$ and group B had excellent results in $76.7 \%(n=23)$ subjects on the 24th week. The results are similar to the results by Haddad et al. who reported $78 \%$ of patients with 
Table 3: Hardware complications for each follow-up

\begin{tabular}{|c|c|c|c|c|c|}
\hline \multirow[b]{2}{*}{ Post-operative day } & \multirow[b]{2}{*}{ Hardware complication } & \multicolumn{2}{|c|}{ Group } & \multirow[b]{2}{*}{ Total $(n=\%)$} & \multirow[b]{2}{*}{$p$ value } \\
\hline & & TBW group $(n=\%)$ & CC screw group ( $n=\%)$ & & \\
\hline \multirow[t]{4}{*}{ 2nd Post-operative day } & No & $29(96.7)$ & $30(100)$ & $59(98.3)$ & 0.313 \\
\hline & Symptomatic hardware & $1(3.3)$ & $0(0)$ & $1(1.7)$ & \\
\hline & Back-out & $0(0)$ & $0(0)$ & $0(0)$ & - \\
\hline & Implant failure & $0(0)$ & $0(0)$ & $0(0)$ & - \\
\hline \multirow[t]{4}{*}{2 Weeks } & No & $29(96.7)$ & $30(100)$ & $59(98.3)$ & 0.313 \\
\hline & Symptomatic hardware & $1(3.3)$ & $0(0)$ & $1(1.7)$ & \\
\hline & Back-out & $0(0)$ & $0(0)$ & $0(0)$ & - \\
\hline & Implant failure & $0(0)$ & $0(0)$ & $0(0)$ & - \\
\hline \multirow[t]{4}{*}{6 Weeks } & No & $26(86.7)$ & $29(96.7)$ & $55(91.7)$ & 0.355 \\
\hline & Symptomatic hardware & $2(6.7)$ & $1(3.3)$ & $3(5)$ & \\
\hline & Back-out & $2(6.7)$ & $0(0)$ & $2(3.3)$ & \\
\hline & Implant failure & $0(0)$ & $0(0)$ & $0(0)$ & - \\
\hline \multirow[t]{4}{*}{12 Weeks } & No & $26(86.7)$ & $29(96.7)$ & $55(91.7)$ & 0.226 \\
\hline & Symptomatic hardware & $4(13.3)$ & $1(3.3)$ & $5(8.3)$ & \\
\hline & Back-out & $2(6.7)$ & $0(0)$ & $0(0)$ & - \\
\hline & Implant failure & $0(0)$ & $0(0)$ & $0(0)$ & - \\
\hline \multirow[t]{4}{*}{24 Weeks } & No & $26(86.7)$ & $29(98.7)$ & 55 (91.7) & 0.226 \\
\hline & Symptomatic hardware & $4(13.3)$ & $1(3.3)$ & $5(8.3)$ & \\
\hline & Back-out & $2(6.7)$ & $0(0)$ & $0(0)$ & - \\
\hline & Implant failure & $0(0)$ & $0(0)$ & $0(0)$ & - \\
\hline
\end{tabular}

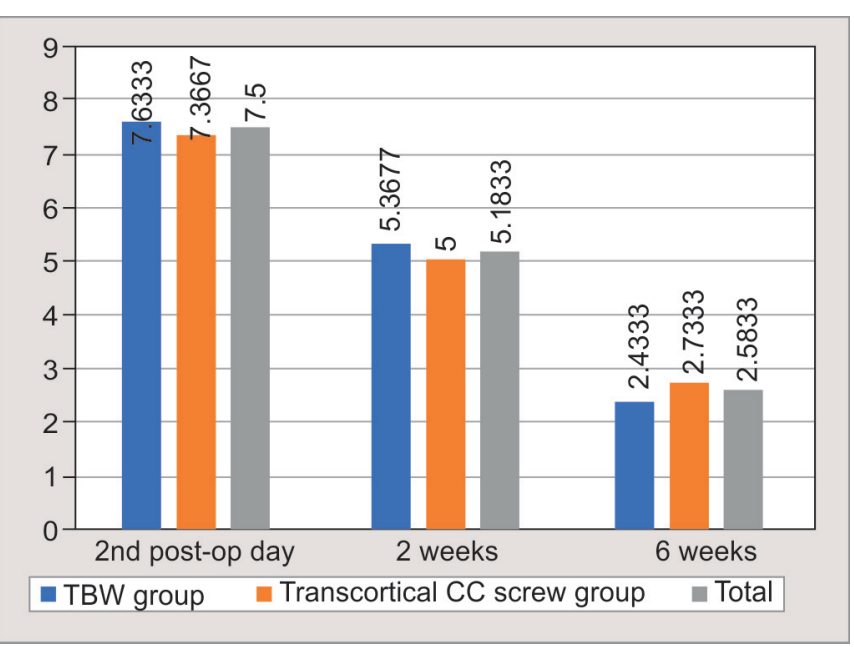

Fig. 5: VAS for the 2nd post-operative day, 2nd week, and 6th postoperative week showing no difference between the two groups

MEPI >80. Panchal et al. also reported excellent results in both TBW and $6.5-\mathrm{mm}$ CCS groups. Lu et al. compared the standard K-wire TBW construct with the TBW construct where a 4.5-mm CCS was used as an anchor and also reported similar MEPI scores. $5,10,13$

The overall infection rate in our study was $5 \%(n=3)$; in the TBW group it was $6.7 \%$ and in the CCS group it was 3.3\% with signs of infection seen on the 2nd post-operative day and 2nd post-operative week. Panchal et al. reported a similar infection rate of $2.94 \%$ in the CCS group. ${ }^{10}$ Raju et al., Woods et al., and Chalidis et al. also reported similar infection rates of $8,8.8$ and $6.5 \%$, respectively. ${ }^{3,11,12}$

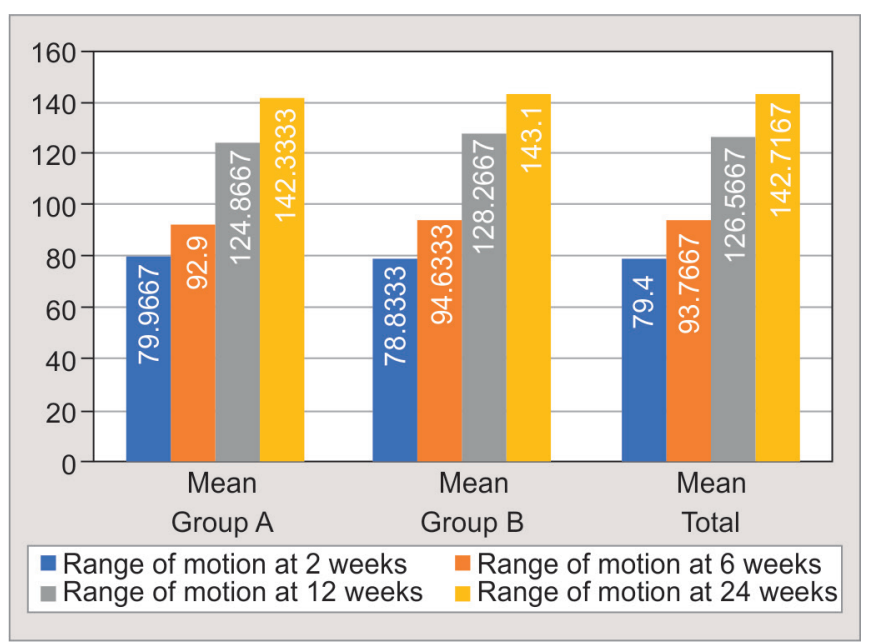

Fig. 6: Mean ROM on each follow-up for the study

Current concepts in bone healing advocate compression at the fracture site for a better union. The primary argument against TBW is that the compression provided by the construct is inferior to that obtained with plates and/or cancellous screws. ${ }^{14,18}$ In our study in the 6th week follow-up, $83.3 \%(n=50)$ showed signs of union on plain radiographs. At the 24 th post-operative week, all patients showed radiological signs of union. Wagner et al., Lu et al., and Boseman et al. reported union at 2-, 3-, and 6-month follow-ups, respectively. ${ }^{5,19,20}$ Woods et al. reported that the odds of non-union were higher for the tension band group than washer group and reported early union in screw and washer groups. ${ }^{12}$ A study by 
Hahn et al. compared TBW, 6.5-mm intramedullary screw, and plate fixation and did not find any statistical differences in compression at the fracture site which support the findings of this study. ${ }^{8}$

TBW has also been shown to have a higher complication rate and re-operation rate with some reporting rates as high as 40 to 92\%. ${ }^{21-24}$ Studies by Haddad et al., Wagner et al., and Chalidi et al. did not report backing out of hardware or loss of fixation which reflects results similar to this study. ${ }^{3,13,20}$ Woods et al. recorded an $8.8 \%$ loss of fixation in all treatment groups and a significant loss in the TBW group in contrast to this study. ${ }^{12}$ In a biomechanical study, Jones et al. found no differences in the fixation of fracture by TBW and transcortical screw for a peak fracture-gap displacement or single cycle to load failure. ${ }^{4}$ This study validates our findings as there were no differences in the incidences of loss of fixation in either group in this study.

Incidence of prominent metalwork following TBW is reported to be as high as 45 to $75 \%$ and re-operation rates of up to $71.7 \% .^{23,25,26}$ The rate of symptomatic hardware in this study was $8.3 \%(n=5)$ at 24 th week follow-up with $13.3 \%$ in TBW group and $8.3 \%$ in CCS group. Woods et al. reported that there was no significant difference in implant removal rates between the screw fixation, plate fixation, and tension band and screw fixation which corroborates with this study. ${ }^{12}$ Panchal et al. reported lower hardware complication rates with TBW (8.82\%) and screw group (5.88\%). ${ }^{10}$ In a study by Uhlmann et al., the hardware removal was substantially less frequent in the percutaneous double screw fixation group than with conventional TBW with 38.5 and $73.1 \%$, respectively contradictory to this study. ${ }^{16}$

Range of elbow motion was analysed separately as the MEPI only included measuring the arc of motion. The ROM at 24th week follow-up in the TBW group was $142.33 \pm 16.11^{\circ}$ and CCS group was $143.1 \pm 10.19^{\circ}$ with no significant statistical difference in between both groups $(p=0.246)$. Bosman et al. reported an average flexion of $145^{\circ}$ (range $135-160^{\circ}$ ) similar to the results of this study. They also reported that the average extension lag was $11^{\circ}$ (range $\left.0-30^{\circ}\right)$. We, however, did not encounter any extensor lag in our study postoperatively. ${ }^{19}$ Contradictory to our findings, Uhlmann et al. reported that in percutaneous double screw method ROM was significantly higher than the conventional TBW method. ${ }^{16}$

This study could have been improved with a longer follow-up which would allow us to record MEPI as well as document the need to remove hardware, late incidences of symptomatic hardware, implant failure, and other complications. A single surgeon did not perform all the surgeries as it was not possible to do so in a high-volume tertiary care hospital; however, all the surgeons were having nearly equal years of clinical experience in managing such fractures. We did not conduct a subset analysis for the outcomes with respect to the fracture pattern.

\section{Conclusion}

Our study shows that there is no statistically significant difference in the times of union, MEPI, post-operative complications, and hardware complications among patients treated with TBW or with CCS for Mayo type A olecranon fractures. We conclude that using two 4.5-mm CCSs is also an acceptable method for the fixation of olecranon fractures in adults.

\section{Clinical Significance}

There were no statistical differences in the clinical-radiological outcomes and complications in Mayo type A olecranon fractures and both methods of fixation are acceptable. The final choice of fixation should be left to the surgeons' discretion.

\section{ACKNOWLedgements}

The authors would like to acknowledge the contributions of the patients for their consent and co-operation.

Ethics approval: This study is a postgraduate thesis and has been granted ethics approval by the Institutional Review Committee of B P Koirala Institute of Health Sciences, Dharan, Nepal.

Consent to participate: Informed consent was obtained from all individual participants included in the study.

Author contributions: All authors contributed to the study conception and design. Material preparation, data collection, and analysis were performed by Siddhartha Sinha, Rajiv Maharjan, Guru P Khanal, Bishnu Pokharel, Nikhil Drolia, Sumit Gupta, Rajesh K Kanojia, and Pashupati Chaudhary. The first draft of the manuscript was written by Siddhartha Sinha and all authors commented on the previous versions of the manuscript. All authors read and approved the final manuscript.

\section{References}

1. Beingessner DM, Pollock JW, King GJW. Elbow fractures and dislocations. In: Court-Brown CM, Heckman JD, McQueen MM, Ricci WM, Tornetta III P, McKee MD, editors. Rockwood and Green's: fractures in adults. 8th edn. North America: Wolters Kluwer; 2015, pp. 1180-1227.

2. Perez E. Fractures of the shoulder, arm, and forearm. In: Canale ST, Beaty JH, editors. Campbell's operative orthopaedics. 12th ed. Philadelphia, PA: Mosby Elsevier; 2012.

3. Chalidis BE, Sachinis NC, Samoladas EP, et al. Is tension band wiring technique the "gold standard" for the treatment of olecranon fractures? A long term functional outcome study. J Orthop Surg Res 2008;3:9. DOI: 10.1186/1749-799X-3-9.

4. Jones TB, Karenz AR, Weinhold PS, et al. Transcortical screw fixation of the olecranon shows equivalent strength and improved stability compared with tension band fixation. J Orthop Trauma 2014;28(3):137-142. DOI: 10.1097/BOT.0b013e31829a25d2.

5. Lu Q, Tang G, Zhao X, et al. Tension band wiring through doublecannulated screws as a new internal fixation method for treatment of olecranon fractures: a randomized comparative study. Acta Orthop Traumatol Turc 2015;49(6):654-660. DOI: 10.3944/AOTT.2015.14. 0330.

6. Nowak T, Mueller L, Burkhart K, et al. Dynamic biomechanical analysis of different olecranon fracture fixation devices-tension band wiring versus two intramedullary nail systems: an in-vitro cadaveric study. Clin Biomech 2007;22(6):658-664. DOI: 10.1016/j. clinbiomech.2007.02.003.

7. Parker J, Conroy J, Campbell D. Anterior interosseus nerve injury following tension band wiring of the olecranon. Injury 2005;36(10):1252-1253. DOI: 10.1016/j.injury.2004.12.028.

8. Hahn A, O'Hara NN, Koh K, et al. Is intramedullary screw fixation biomechanically superior to locking plate fixation and/or tension band wiring in transverse olecranon fractures? A cadaveric biomechanical comparison study. Injury 2020;51(4):850-855. DOI: 10.1016/j.injury.2020.02.059.

9. Hutchinson DT, Horwitz DS, Ha G, et al. Cyclic loading of olecranon fracture fixation constructs. J Bone Joint Surg Am 2003;85(5):831-837. DOI: 10.2106/00004623-200305000-00010.

10. Panchal HC, Bhabhor PK. $6.5 \mathrm{~mm}$ cancellous screw with washer vs tension band wiring for fractures of the olecranon. Int J Orthop 2019;5(4):971-975. DOI: 10.22271/ortho.2019.v5.i4q.1803.

11. Raju S, Gaddagi RA. Cancellous screw with tension band wiring for fractures of the olecranon. J Clin Diagn Res 2013;7(2):339-341. DOI: 10.7860/JCDR/2013/4450.2762. 
12. Woods BI, Rosario BL, Siska PA, et al. Determining the efficacy of screw and washer fixation as a method for securing olecranon osteotomies used in the surgical management of intraarticular distal humerus fractures. J Orthop Trauma 2015;29(1):44-49. DOI: 10.1097/ BOT.0000000000000131.

13. Haddad B, Khan W, Zaghloul A, et al. Fixation of olecranon fractures and osteotomies using compression screws: a simple solution to a common problem. A study of cases. Ortop Traumatol Rehabil 2013;15(4):341-346. DOI: 10.5604/15093492.1073833.

14. Brink $P$, Windolf $M$, De Boer $P$, et al. Tension band wiring of the olecranon: is it really a dynamic principle of osteosynthesis? Injury 2013;44(4):518-522. DOI: 10.1016/j.injury.2012.08.052.

15. Wagener ML, Driesprong M, Heesterbeek PJ, et al. Biomechanical evaluation of three different fixation methods of the Chevron osteotomy of the olecranon: an analysis with Roentgen Stereophotogrammatic Analysis. Clin Biomech 2013;28(7):752-756. DOI: 10.1016/j.clinbiomech.2013.06.011.

16. Uhlmann M, Barg A, Valderrabano V, et al. Treatment of isolated fractures of the olecranon: percutaneous double-screw fixation versus conventional tension band wiring. Unfallchirurg 2014;117(7):614-623. DOI: 10.1007/s00113-013-2389-y.

17. Wolfgang $G$, Burke $F$, Bush $D$, et al. Surgical treatment of displaced olecranon fractures by tension band wiring technique. Clin Orthop Relat Res 1987;224:192-204. DOI: 10.1097/00003086-198711000-00026.

18. Wilson J, Bajwa A, Kamath V, et al. Biomechanical comparison of interfragmentary compression in transverse fractures of the olecranon. J Bone Joint Surg Br 2011;93(2):245-250. DOI: 10.1302/0301-620X.93B2.24613.
19. Bosman WMP, Emmink BL, Bhashyam AR, et al. Intramedullary screw fixation for simple displaced olecranon fractures. Eur J Trauma Emerg Surg 2020;46:83-89. DOI: 10.1007/s00068-019-01114-4.

20. Wagener ML, Dezillie M, Hoendervangers $Y$, et al. Clinical results of the re-fixation of a Chevron olecranon osteotomy using an intramedullary cancellous screw and suture tension band. Strategies Trauma Limb Reconstr 2015;10(1):1-4. DOI: 10.1007/ s11751-015-0211-9.

21. Amini MH, Azar FM, Wilson BR, et al. Comparison of outcomes and costs of tension-band and locking-plate osteosynthesis in transverse olecranon fractures: a matched-cohort study. Am J Orthop (Belle Mead NJ) 2015:44(7):E211-E215.

22. Koziarz A, Woolnough $T$, Oitment $C$, et al. Surgical management for olecranon fractures in adults: a systematic review and meta-analysis. Orthopedics 2019;42(2):75-82. DOI: 10.3928/01477447-20190221-03.

23. Romero JM, Miran A, Jensen $\mathrm{CH}$. Complications and re-operation rate after tension-band wiring of olecranon fractures. J Orthop Sci 2000;5(4):318-320. DOI: 10.1007/s007760070036.

24. Schliemann B, Raschke MJ, Groene P, et al. Comparison of tension band wiring and precontoured locking compression plate fixation in Mayo type IIA olecranon fractures. Acta Orthop Belg 2014;80(1): 106-111.

25. Macko D, Szabo RM. Complications of tension-band wiring of olecranon fractures. J Bone Joint Surg Am 1985;67(9):1396-1401. DOI: 10.2106/00004623-198567090-00015.

26. Villanueva $\mathrm{P}$, Osorio $\mathrm{F}$, Commessatti $\mathrm{M}$, et al. Tension-band wiring for olecranon fractures: analysis of risk factors for failure. J Shoulder Elbow Surg 2006;15(3):351-356. DOI: 10.1016/j.jse.2005.08.002. 